
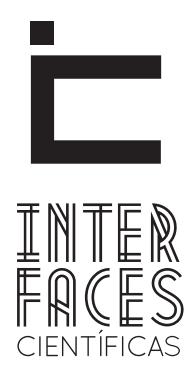

DIREITO

\title{
O DIREITO ENTRE 0 ESTADO E 0 ESTADO DE DIREITO: REVISITANDO A TEORIA DO DIREITO E DO ESTADO DE LEÓN DUGUIT
}

Ian Pimentel Gameiro ${ }^{1}$

\section{RESUMO}

O artigo objetiva oferecer uma leitura ampla e detalhada da pouco estudada obra de León Duguit. Inicia, pois, com a reconstituição dos antecedentes teóricos que sustentam o seu pensamento, a saber, as teorias de Herbert Spencer e Émile Durkheim, e segue, a partir daí, com a sua concepção do Estado, do Direito, e do Estado de Direito. A teoria de Duguit, no contexto atual em que se questiona o papel do
Estado e do Direito a partir de fenômenos como o constitucionalismo multinível e o cosmopolitismo societal, pode oferecer respostas interessantes e daí a necessidade de revitalizá-la.

\section{PALAVRAS-CHAVE}

Estado. Direito. Estado de Direito. 


\section{ABSTRACT}

The article aims to provide a comprehensive and detailed reading about the little studied Leon Duguit's work. It starts, then, with the reconstitution about the theoreticala background underpinning their thinking, namely the theories of Herbert Spencer and Emile Durkheim, and continues from there, with his conception of the State, the Law, and the Rule of Law. Duguit's theory, in the current context, questioning

\section{RESUMEN}

El artículo pretende ofrecer una lectura comprensiva y detallada de la obra de Leon Duguit, que muy poco ha sido estudiada. Comienza, entonces, con la reconstitución de la base teórica que sustenta su pensamiento, a saber, las teorías de Herbert Spencer y Emile Durkheim, y continúa desde allí, con su concepción del Estado, la ley y el Estado de Derecho. La teoría de Duguit, en el contexto actual, cuestionan- the role of the State and Law from phenomena such as multilevel constitutionalism and societal cosmopolitanism, can offer interesting answers and hence the need to revitalize it.

\section{KEYWORDS}

State. Law. Rule of Law.

do el papel del Estado y la Ley de fenómenos como el constitucionalismo multinivel y el cosmopolitismo de la sociedad, puede ofrecer respuestas interesantes y por lo tanto la necesidad de revitalizarlo.

\section{PALABRAS CLAVE}

Estado. Derecho. El estado de derecho. 


\section{INTRODUÇ̃̃̃O}

O Direito entre o Estado e o Estado de Direito propõe-se a dissertar sobre antiga, porém atualíssima, teoria do Estado, do Direito, e da relação que estes dois elementos da vida social mantém entre si.

O tema se justifica não só porque se ocupa do pensamento de León Duguit ${ }^{1}$, mas, sobretudo, porque revigora no contexto específico do constitucionalismo multinível, interconstitucionalidade, multiculturalidade e cosmopolitismo a discussão em torno da concepção do Estado, do seu real papel social e da sua relação de subordinação com o Direito.

Isso implica, pois, em se considerar necessário reconhecer o contexto jurídico-político e social em que está inserta a doutrina de Duguit: a França da segunda metade do século XIX até o primeiro quartel do século XX. Aliás, a boa leitura da sua obra, a sua compreensão adequada, implica em reconhecer as influências, dessa específica condicionalidade histórico-social, sobre o seu pensamento.

Isso porque Duguit acompanhou de perto uma França efervescente politicamente. Uma França que se afirmava republicana, como o Estado da "coisa pública”, pelo menos sob o ponto de vista espiritual, mas que não conseguia se sustentar politicamente como tal; um Estado que basicamente alternava entre curtas Repúblicas e longas monarquias.

Duguit se afirmava republicano, e toda sua construção doutrinária do Estado e do Estado de Direito tinham como objetivos se opor às teorias autoritárias da Herrschaft que prosperavam na Alemanha e se prestavam, de certo modo, a sustentar o poder político como "direito subjetivo" dos que estavam à testa do ente estadual.

1. Pierre Marie Nicolas León Duguit (1859-1928) foi um jurista francês especializado em direito público, nomeadamente em Direito Constitucional e Teoria do Estado, que exerceu sua carreira acadêmica na Universidade de Bordeaux, onde posteriormente se tornou decano, no período da França oitocentista (REALE, 2002, p. 439).
É desse ponto de partida que se deve ler Duguit, e partindo dele, então, traçar-se-á as linhas da sua concepção do Estado e do Estado de Direito, a partir do Direito, permeando a exposição com a reconstrução dos diálogos que estabeleceu com Spencer e Durkheim, os teóricos que lhes forneceram as bases fundamentais sobre as quais se assenta seu pensamento.

A despeito das inúmeras "certidões de óbito" que lhe foram sendo passadas ao longo da história, o Estado, assim entendido como produto cultural e político da humanidade, vai resistindo, e, portanto, buscar no passado as respostas para as dificuldades presentes, marcadamente as que revigoram os questionamentos em torno da sua real função social em um contexto político cada vez mais condicionado às exigências jurídicas do plano internacional se afigura alternativa viável.

Não constitui objetivo deste artigo, no entanto, cumpre logo advertir, oferecer a partir de Duguit as respostas para as inquietudes e complexidades contemporâneas envolvendo a estatalidade. É seu objetivo, na verdade, instigar o leitor a refletir e encontrá-las, considerando agora a proposta formulada por esse autor em tempo igualmente conturbado na história do Estado.

\section{ANTECEDENTES TEÓRICOS}

A concepção de Estado e de Estado de Direito desempenha papel fundamental na Teoria do Direito, proposta por León Duguit. Melhor dizendo: só se explica qual sua concepção de Estado e de Estado subordinado ao Direito, perpassando por imperiosa necessidade metodológica, pela sua compreensão acerca do Direito e de seu fundamento.

Como Duguit é pouco estudado no contexto brasileiro, seja pela Filosofia do Direito no que concerne à sua concepção da normatividade, seja pela dogmá- 
tica constitucional no que se refere à sua concepção de Estado e de Estado de Direito, quase nada se sabe sobre os precedentes teóricos que esteiam toda a sua doutrina, quer seja a do Estado quer seja a do Direito.

Assim, em obséquio ao apego e rigor científico, exigidos pela proposta do autor, é justo iniciar esse percurso de reconstrução a partir dos teóricos que forneceram a Duguit as bases sobre as quais sustenta o seu pensamento e com quem este dialogou intensamente.

No entanto, uma nota preliminar é importante: a razão pela qual propositalmente excluiu-se Jean-Jacques Rousseau e o seu republicanismo liberal do objeto de análise, a despeito de sua influência sobre o autor, só se justifica porque tal concepção é adotada por Duguit na perspectiva da filosofia política.

Isto é, o autor não dialoga diretamente com Rousseau; não utiliza suas ideias para fundamentar um dado pensamento. Duguit adota a ideia da república rousseauniana e a defende como um ideal político, como concepção politicamente adequada da vida em sociedade e do Estado.

Assim como poderia entender que a monarquia é a forma política adequada de Estado por favorecer tais ou quais benefícios à sociedade, e construir uma tese, defendendo tal forma de constituição da unidade política, Duguit o faz em relação à República. Daí porque se diz que a ideia de república em Duguit é assumida na perspectiva da filosofia política, uma vez que dependente, por isso mesmo, da sua concepção da vida e da boa vida em sociedade.

\subsection{ORGANICISMO EVOLUCIONISTA DE HERBERT SPENCER}

Se os séculos XVI e XVII foram os séculos das ciências exatas, das transformações matemáticas, físicas e astronômicas, o século XVIII sem dúvida foi o das ciências biológicas (LARAIA, 2005, p. ?). Os grandes descobrimentos sobre a natureza, a revelação científica de algumas de suas leis e o peso intelectual que detinham os seus investigadores ditaram os rumos da Ciência naquele período.

As explicações sobre a vida, antes dadas numa perspectiva algorítmica, passaram a ser oferecidas na perspectiva naturalística/biológica. E a vida em sociedade não tardou em ser, também, analisada segundo esse ponto de vista.

O marco teórico que sustentou o organicismo evolucionista enquanto teoria sociológica fora, inquestionavelmente, o estudo acerca da evolução biológica das espécies lançado por Charles Darwin, e vários foram aqueles que se serviram das bases teóricas lançadas por Darwin para explicar a vida em sociedade.

Foi com Herbert Spencer, no entanto, que a escola orgânica se destacou.

A ideia de Spencer (COSTA, 2005, p. 70), representando aqui o núcleo em torno do qual girava o pensamento da escola orgânica evolucionista, consistia basicamente em reconhecer a sociedade como um organismo vivo, dotado de sistemas e funções específicas, interdependentes e dispostas com vistas à manutenção do todo social, que teria evoluído do mais primitivo ao mais complexo "[...] através de um processo de diferenciação estrutural apoiado na superioridade de adaptação através da seleção natural” (BUTTEL, 1992, p. 72).

Orgânica a sociedade, porque estaticamente identificada suas funções pelos diversos, porém conexos, órgãos que a compõe; evoluída haja vista ser dotada de órgãos mais adaptados estruturalmente às suas funções, em razão da seleção natural pela qual passaram e, consequentemente, porquanto mais integrados ao complexo social em razão da sua maior especialização.

Por ora é a noção que importa ter presente, mas ver-se-á adiante que a ideia vendida pela escola orgânica evolucionista fora fundamental para que Duguit desenvolvesse sua concepção do Estado. 


\subsection{A SOCIOLOGIA EXPERIMENTALISTA DE ÉMILE DURKHEIM}

Embora Durkheim fosse adepto com reservas do organicismo defendido por Spencer (BUTTEL, 1992, p. 73), assim como Marx, Engels (SOARES, 2009, p. 65) e praticamente todos os teóricos clássicos, outras foram as suas contribuições para a ciência, particularmente para a sociologia: a noção de solidariedade e a concepção do fato social.

Do organicismo e da sua ideia fundante de que a sociedade é segmentada em órgãos com funções específicas, porém interconexas, Durkheim assentou sua concepção de solidariedade como fundamento da lei social que impelia os homens a se acharem vinculados uns com os outros e com o todo. Da psicologia experimental de Wilhelm Wundt (ARAÚJO, 2009, p. 214), de quem foi aluno, Durkheim se serviu do método da observação para constatar que o comportamento humano não era moldado somente por regras escritas ou prescrições explícitas; tal regramento comportamental implícito, também, exercia sua influência sobre o homem (SABADELL, 2010, p. 47).

A construção de Durkheim se inicia, pois, com essas duas constatações.

A primeira consiste em perceber que o homem não se basta; está condenado a uma vida gregária, mais ou menos intensa conforme se ache em maior ou menor grau de relacionamento com os demais, vínculo ao qual se referiu como "solidariedade social" em seu célebre "A divisão do trabalho social" (DURKHEIM, 1999, p. 85-109).

A segunda, pois, resulta da percepção de que essa interrelação entre os homens é determinada por um conjunto de condições, de maneiras, de pensamentos, enfim, por um conjunto de normas, prescritas e não prescritas, que exercem certa influência sobre os seus comportamentos, circunstância que denominou de fato social (DURKHEIM, 2007, p. 1-14).
Durkheim articula, então, essas duas constatações para afirmar que se uma dada sociedade se mantém vinculada, e os seus órgãos assim se relacionam, tendo como nota de coesão os "fatos sociais" dos costumes, da tradição, da religião ou da mera semelhança, o tipo de solidariedade que lhe é particular é o da "solidariedade mecânica".

\begin{abstract}
Tais sociedades impõem aos seus membros deveres particularmente rígidos. Todos devem respeitar as regras estabelecidas pela autoridade. Os valores sociais decorrem da tradição e da religião e o grupo organiza-se como uma verdadeira comunidade, fundamentada em relações de parentesco e na preservação da propriedade coletiva. (SABADELL, 2010, p. 48).
\end{abstract}

Se, por outro lado, essa mesma sociedade passa a se vincular, e os seus órgãos a se relacionar, a partir do "fato social" do trabalho, especializado e interdependente, estará presente em causa, então, a "solidariedade orgânica”.

\begin{abstract}
A sociedade moderna caracteriza-se, ao contrário, pela solidariedade orgânica (ou por dessemelhança). Trata-se de uma sociedade complexa, fundamentada na divisão do trabalho, segundo o princípio da especialização. $O$ indivíduo não se vincula diretamente a valores sociais, não está submetido a liames tradicionais, a obrigações religiosas ou comunitárias. A solidariedade cria-se através de redes de relacionamento entre indivíduos e grupos, onde cada um deve respeitar as obrigações assumidas por contrato. (SABADELL, 2010, p. 49).
\end{abstract}

À maior interdependência entre os órgãos caracterizadora da sociedade mais complexa, Durkheim deu o nome de "solidariedade orgânica"; à menor interdependência típica da sociedade menos complexa o autor chama de "solidariedade mecânica" (DURKHEIM, 1999, p. 85-109).

A ideia de solidariedade social e da sua dupla distinção, como originalmente pensada por Durkheim, será fundamental para Duguit desenvolver a sua teoria acerca do que constitui para si o fundamento do Direito, a sua concepção sobre a normatividade e como ela se constrói, e o porquê, ao fim e ao cabo, deve o Estado se submeter ao Direito. 


\section{ESTADO}

As bases teóricas fincadas em ensinamentos da sociologia de Durkheim, de Spencer e de todos os outros que de uma ou outra forma se perfilhavam à corrente do organicismo evolucionista e do experimentalismo sociológico dos séculos XVIII e XIX, forçosamente fizeram Duguit incluir-se, segundo classificação epistemológica do Direito e do pensamento jurídico, na escola sociológica e antiformalista do Direito.

É sociológica porque nega, de um lado, a autonomia do Direito e do pensamento jurídico e o explica a partir dos esquemas e métodos próprios da sociologia, predominantemente sob o prisma do fato social; antiformalista, de outro, porque repudiava a lei como forma e questionava "[...] o rigor conceitualista e o distanciamento entre a teoria jurídica da época e a dinâmica social" existente (DRI, 2010, p. 5).

Essa é a pedra de toque do modo de pensar do autor e nesse contexto é que se insere a sua teoria do Estado.

A doutrina de Duguit rejeita de modo veemente a ideia de que o Estado constitui-se como entidade coletiva autônoma e soberana, que existe por si e para si sem considerar que "[...] a sociedade é formada de indivíduos e de que só estes possuem realidade concreta em razão de cujas exigências a coletividade se organiza” (REALE, 2002, p. 440).

Billier e Maryioli (2007, p. 270) afirmam que "O Estado, começa ele por observar, não existe sob a forma de poder público ou de soberania. Estes são conceitos vazios, desprovidos de qualquer referência semântica, por detrás dos quais está a diferenciação entre os governantes e governados".

Para construir sua teoria do Estado, Duguit retoma, então, como se disse antes, a ideia básica do organicismo evolucionista, segundo a qual a sociedade se assemelharia a um organismo vivo do- tado de sistemas e funções específicas e interdependentes que teria evoluído do mais primitivo ao mais complexo por meio da seleção natural pela qual foram selecionados os órgãos mais adaptados estruturalmente às suas funções.

E afirma: não se trata o Estado de uma ficção jurídica; tampouco de pessoa coletiva e soberana. O Estado nada mais é do que o resultado de um processo diferencial, de natureza social e histórica, pelo qual se distinguiram os fracos dos fortes. É, pois, uma diferenciação provocada pela própria sociedade, que se explica como produto da evolução social, e cujo produto (o Estado) necessita receber uma legitimação somente atribuível pela própria comunidade, por meio do Direito, tendo em conta a necessidade de reforço ou proteção da "solidariedade social", da interdependência social (DUGUIT, 1903, p. 1).

Isso é claro em seu pensamento, conforme exposto:

Para nos conformar com o hábito, e porque é cômodo, utilizaremos ordinariamente a palavra Estado; fica bem entendido, porém, que, no nosso modo de pensar, esta palavra não designa, em absoluto, essa pretensa pessoa coletiva e soberana, que não passa de um fantasma, mas os homens reais que de fato são os detentores da força. (DUGUIT, 1923, p. 31).

Isto corresponde a dizer que Duguit, considerando o Estado como o grupo de pessoas detentoras da maior força em virtude da natural evolução social dos indivíduos, julga ser necessário legitimar-se, pelo Direito, em benefício da solidariedade social e com o escopo de evitar a sua utilização arbitrária, a força maior e superior da qual esse específico corpo de indivíduos se vale.

Daí se extrai, então, dois pontos capitais da Teoria do Estado de Duguit.

0 primeiro diz quanto à natureza do poder político, da força maior que faz o todo prestar obediência a alguns, e se traduz em palavras da seguinte forma: 
O poder governamental existe, respondeu ele, não há dúvida, e não pode deixar de existir. Eu tão-somente nego que seja um direito. Afirmo que aqueles que detêm esse poder detêm um poder de fato e não um poder de direito. Dizendo que eles não têm o poder público, quero dizer que eles não têm o direito de formular ordens e que as manifestações de sua vontade não se impõem como tais aos governados. (DUGUIT apud REALE, 2000, p. 77).

A segunda, pois, diz quanto ao fato de o Estado somente legitimar-se quando utilizar sua maior força em benefício da sociedade, reforçando ou protegendo a "solidariedade orgânica" ou interdependência entre os indivíduos. Essa noção, aliás, é fundamental para que se compreenda sua Teoria do Direito.

\section{DIREITO}

Como se viu, a noção de evolução social e diferenciação dos indivíduos em dada sociedade, própria do organicismo evolucionista, foi fundamental para que Duguit constatasse a verdadeira realidade que estava associada ao termo Estado: grupo de pessoas que detém a maior força ou poder no âmbito de certo contexto político.

E dessa ideia de evolução e diferenciação social, "temperada" com a doutrina de Durkheim, acerca da divisão do trabalho e da dicotomia essencial que estabelece em relação à solidariedade social é que Duguit parte para a elaboração da sua concepção do Direito, do que constitui seu fundamento e como a normatividade surge ou se forma na sociedade.

O autor deixa, aliás, textualmente expressa sua vinculação ao pensamento de Durkheim

É Durkheim, em seu belo livro "A divisão do trabalho social", o primeiro a determinar a natureza íntima da solidariedade social e a mostrar suas formas essenciais: a solidariedade por similitudes e a solidariedade por divisão do trabalho; ele denomina a primeira, também, de solidariedade mecânica, e a segunda de solidariedade orgânica. (DUGUIT, 1923, p. 9. Tradução nossa).
Duguit inicia sua tese, então, considerando como a verdadeira razão que aproxima os homens e os obriga a viver em comunidade, a sua incapacidade para dar conta da vida, sua insuficiência em dar respostas satisfatórias a todas as necessidades quotidianas.

O homem, para ele, não é uma ilha, e não tem possibilidade de ser, sob o prisma particular da sua capacidade, autossuficiente; ao contrário, a limitação da força humana é uma realidade irrecusável, e qualquer teoria ou pensamento social que escape dessa consideração está invariavelmente fadada ao insucesso.

Dessa trágica e inelutável condição da existência humana, Duguit extrai duas verdades para si fundamentais.

Uma, a de que o homem está condenado a viver, por sua própria natureza, uma vida de comunidade, uma vida de partilha. Diz ele:

\begin{abstract}
Nosso ponto de partida é o fato incontestável de que o homem vive em sociedade, sempre viveu em sociedade e não pode viver mais que não em sociedade com seus semelhantes, e que a sociedade humana é um fato primário e natural, e em maneira alguma produto ou resultado da vontade humana. Todo homem, forma, pois, parte de um grupo humano; o tem formado e formará sempre, por sua própria natureza. (DUGUIT, 1923, p. 5. Tradução nossa).
\end{abstract}

Segunda, pois, a de que na vida em sociedade, vida comunal pensada nos termos do organicismo evolucionista, considera operar-se uma natural evolução e diferenciação social, afinal de contas os indivíduos possuem interesses e predisposições diferentes, carências distintas, e vocações indeterminadas para um campo igualmente múltiplo e indeterminado de ação (REALE, 2002, p. 442). Sua concepção mesmo do Estado se assenta, como foi mostrado em tópico precedente, nessa ideia.

Diante dessas duas verdades, Duguit afirma: "a solidariedade é um fato social”. Um fato social, porque ante a incapacidade natural do homem, impele-o, condiciona-o a uma vida de sociedade, de permuta 
com seus semelhantes, a fim de que as suas necessidades singulares sejam supridas pelas respostas e habilidades dos outros.

A vida comunal só se justifica mesmo na medida em que, reconhecendo o indivíduo sua incapacidade diante da vida e da natureza, busca em seus semeIhantes as respostas e soluções das quais precisa para continuar dando curso ao seu plano de vida.

Com efeito, ainda que Duguit considere a existência de comunidades cuja coesão ainda se assente em elementos particularmente rígidos como os da religião, dos costumes e da tradição, ainda assim, nessas sociedades, um nível ínfimo de divisão do trabalho terá se operado, porque mais uma vez volta-se ao fato inescapável de que nem todos poderão solucionar a integralidade dos seus problemas privados, e a solução para questões singularmente insolvíveis será buscada no próximo.

Os homens distribuem-se em campos múltiplos de ação. Cada qual realiza uma tarefa, que pode estar ou não de acordo com as suas tendências naturais, mas que ele deve realizar, momentânea ou definitivamente, para poder subsistir. A atividade particular de cada homem deve harmonizar-se com as atividades dos outros, daí resultando o estabelecimento de uma divisão geral do trabalho, que é o fato fundamental da sociedade, segundo Duguit. 0 que constitui a sociedade e the dá estrutura é a divisão do trabalho. (REALE, 2002, p. 442).

Assim, para Duguit, importando nesse ponto o pensamento de Durkheim, uma sociedade será mais evoluída quanto mais se operar a divisão social do trabalho, com o consectário lógico de, quanto mais especializada, mais coesos e interdependentes estarão os indivíduos.

A essa interdependência entre os indivíduos, originada pela divisão e especialização do trabalho, Durkheim chamou de "solidariedade orgânica" e Duguit, aproveitando integralmente essa noção, a tem para si como o "fundamento do Direito".

A propósito, Miguel Reale traduz em exemplos a dicotomia que Durkheim estabelece em relação à solidariedade:
Solidariedade mecânica é aquela que se estabelece quando duas ou mais pessoas, tendendo a um mesmo fim, praticam a mesma série de atos. Num exemplo elementar, podemos lembrar o esforço conjugado de cinco ou dez indivíduos para levantar um bloco de granito. Este é um caso de coordenação do trabalho, que tem como resultado a solidariedade mecânica. Quando, porém, os indivíduos, para realizar determinados fins, para alcançar determinada meta, não praticam os mesmos atos, mas atos distintos e complementares, temos a divisão de trabalho orgânica, que tem como resultado a solidariedade orgânica. (REALE, 2002, p. 441-442).

Duguit considera, pois, que o Direito é a um só tempo um fato social e uma necessidade da sociedade. Um fato posto que se traduz em um conjunto de regras sociais expressas condicionantes da vida humana; e uma necessidade porque predispõe-se vocacionalmente a regular um modo predeterminado e organizado de reação da sociedade ante a violação do seu princípio fundante, a "solidariedade orgânica“.

Em uma sociedade especializada, fragmentada de acordo com o trabalho, cada indivíduo detém uma função social específica, um trabalho a desenvolver. E é dever de cada membro desenvolver sua função da melhor maneira possível, entregar para a sociedade a melhor prestação que puder dar consideradas as suas habilidades e limitações; ao fim e ao cabo, sua atuação deve aumentar e realizar ainda mais a solidariedade orgânica.

Quando o indivíduo deixa de cumprir seu papel, a sociedade especializada deixa de receber certa prestação com a qual contava, e, consequentemente, uma reação em retaliação a essa conduta transgressora deve ocorrer. 0 fundamento do Direito, portanto, é este: o fato incontestável da interdependência social dos membros de certa comunidade; e o seu papel consiste exatamente em estabelecer regras preordenadas de reforço da solidariedade social, de um lado, e um modo predeterminado e organizado de reação ante a ofensa à solidariedade, de outro. 
O Estado mesmo, tido por Duguit como o conjunto de pessoas que historicamente se diferenciaram das demais pela força, só se legitima quando, por meio das regras jurídicas, fornece aos cidadãos os serviços públicos de que necessitam para reforçar a solidariedade, a um tempo, e quando oferece proteção à solidariedade, por meio do uso juridicamente autorizado da força, pelas punições que impõe àqueles que a aniquilam de certo modo.

Bem, mas se o fundamento do Direito é o fato da "solidariedade orgânica" e a sua razão de existir repousa na necessidade de se estabelecer um modo predeterminado e organizado de reforço e proteção à incontestável interdependência humana, no que consistiria ao fim e ao cabo o próprio Direito?

\section{Duguit responde essa questão da seguinte forma.}

Cada sociedade possui no seu interior um modo muito particular de agir, pensar e de sentir. Esse conjunto de pensamentos, de sentimentos e de atitudes coletivas constitui um verdadeiro regramento da vida em sociedade, e inquestionavelmente exerce influência sobre os indivíduos, seja para reprimi- los seja para estimulá-los, tendo-se em conta o dever de reforço à solidariedade. Foi o que Durkheim chamou de "fato social".

Esse regramento da vida social, e nisso consiste o ineditismo de seu pensamento, está escalonado em três patamares distintos, segundo a intensidade do risco que a violação das suas disposições implicam à solidariedade: o das regras morais, o das regras econômicas e o das regras jurídicas.

As regras morais representam o regramento mais geral e particularmente mais rígido da vida social. Isso porque traduzem implicitamente a ideia de como os indivíduos devem se relacionar para que a solidariedade orgânica seja reforçada; de como devem agir para coletivamente viver bem.
Usar determinada vestimenta em certa ocasião, manter conduta proba e urbana no trato com os demais, ser honesto, praticar caridade, dentre várias outras regras de essência eminentemente moral traduzem o que aquela determinada comunidade espera dos seus componentes na relação que são obrigados a manter. É a reprodução da velha máxima popular: se somos obrigados a nos relacionar, procuremos fazê-lo da melhor maneira possível.

A violação de uma regra moral corresponde, então, ao fim e ao cabo, a uma ofensa dirigida a toda coletividade, e não a um indivíduo em específico. Tal conduta afrontosa, como andar desnudo pelas ruas, comporta um juízo crítico e uma tomada de postura por parte da coletividade, que sente ameaçada a sua unidade pela prática do ato violador em referência.

E aí a sua repreensão será tanto mais intensa, quanto mais ameaçador for 0 ato infrator à coesão social. Daí se explica o fato de Duguit entender que a moral social representa o regramento mais favorecedor da solidariedade orgânica, uma vez que sua violação sempre e em todo caso corresponderá a uma ofensa irrogada contra a própria sociedade (REALE, 2002, p. 445).

Mas se as regras morais representam o regramento mais geral e particularmente mais rígido da vida social, o mesmo já não se pode dizer das regras econômicas. Isso porque o regramento econômico da sociedade traduz-se na ideia de como os recursos devem ser socialmente geridos pelos indivíduos para reforçarem a solidariedade orgânica; de como esses devem administrar os bens para que vivam bem.

Fazer economias, utilizar somente o essencial e não consumir mais do que se possui traduzem-se em pequenas mensagens emitidas pela sociedade acerca do que espera dos indivíduos que a compõe, em relação à gestão dos bens e recursos disponíveis.

Diferentemente do que ocorre quando uma regra moral é violada, é perfeitamente possível que a violação de uma regra econômica não atinja a sociedade, 
que diga respeito somente ao indivíduo que a violou, sendo ele mesmo o seu principal prejudicado (REALE, 2002, p. 445).

A regra segundo a qual não se deve gastar mais do que se possui interessa a toda coletividade, é verdade, haja vista não fosse assim os recursos disponíveis facilmente se esgotariam. Mas ao mesmo tempo em que interessa à integralidade social, interessa mais ainda ao próprio indivíduo, o primeiro e imediato prejudicado.

Com efeito, a violação de uma regra moral sempre importa numa ofensa irrogada contra toda a sociedade, mas nem toda violação de ordem econômica importará assim num imediato desacato diferido contra a coletividade.

E nisso é que se diferenciam as normas morais das normas econômicas segundo Duguit.

\section{Mas e o Direito?}

Bem, para Duguit, o Direito consiste, em suma, no regramento da vida social composto por normas morais e econômicas, as mais importantes, consideradas essenciais para o reforço e proteção da solidariedade orgânica, que a sociedade entende devam ser elas garantidas pela força do Estado.

Isto é, o Direito se forma, e assim é concebido, como o conjunto de normas morais e econômicas garantidas pela força estatal por exigência da própria sociedade. Diz ele que "Uma regra econômica ou moral torna-se norma jurídica quando na consciência da massa dos indivíduos, que compõem um grupo social dado, penetra a ideia de que o grupo ou os detentores da maior força podem intervir para reprimir as violações dessa regra” (DUGUIT, 1923, p. 53).

Por isso o autor afirma categoricamente que o Estado, o grupo dos detentores da maior força, só se legitima quando, de um lado, usa sua potência para reforçar a solidariedade orgânica por meio da concessão aos indivíduos dos serviços públicos dos quais necessitam para desempenhar mais adequadamente suas funções, e, de outro, quando utiliza essa mesma força pelo Direito para punir aqueles que violem as regras jurídicas.

\section{Eis o Direito para León Duguit.}

Uma última curiosidade antes de encerrar o tópico presente.

Duguit é conhecido, e assim foi chamado por Maurice Hariou (REALE, 2000, p. 76), um de seus contemporâneos, de "anarquista de cátedra". E assim foi chamado não somente pela sua concepção do Estado e do Direito completamente revolucionária e avessa ao pensamento dominante no período, mas, sobretudo, pela introdução da ideia de função social no Direito.

Para Duguit, aquilo que se concebe por direito subjetivo deve ser concebido, na verdade, como o dever jurídico de reforço da "solidariedade". Isto é, as garantias jurídicas postas em benefício do indivíduo, como o direito a liberdade, por exemplo, devem ser interpretadas como um dever que obriga o indivíduo a agir em reforço da solidariedade; no caso, sendo livre o suficiente para desenvolver suas potencialidades (DUGUIT, 1912, p. 37).

Assim, as concessões jurídicas grafadas sob a nomenclatura de "direitos subjetivos" que se fazem aos indivíduos têm uma função social, qual seja, a de propiciar a partir do seu âmbito normativo o reforço da solidariedade social.

\section{ESTADO DE DIREITO}

A concepção de Duguit acerca do État Légal é tranquilamente dedutível da sua construção acerca do Estado e do Direito.

A ideia de que o Estado constitui o grupo das pessoas detentoras da maior força, quando articulada 
com a ideia de que o Direito constitui o conjunto de regras morais e econômicas que a sociedade exige sejam garantidas pela força, deixa em evidência a concepção de Duguit acerca do tema: o Estado é de Direito, e só pode ser assim, porque somente a sociedade tem o poder de formá-lo e a autoridade de dizer quando o ente estadual pode, por meio das regras jurídicas, usar a força em seu benefício.

Em outras palavras: a sociedade compreende que o Estado, à maneira como todos os outros indivíduos, está a serviço de uma função dentro do contexto social, ofício igualmente submetido à realização da solidariedade orgânica. E compreende, também, que a sua peculiaridade é justamente a de deter a maior força. O Estado é de Direito, é condicionado à normatividade, porque as regras jurídicas surgem a partir da criação social, no momento em que a sociedade exige do Estado, posto estruturalmente a serviço da solidariedade social, a garantia de determinada norma moral ou econômica pela força.

O Direito se impõe ao indivíduo, então, da mesma forma que se impõe ao Estado. Daí porque somente se legitima o ente estadual quando usa sua força nos momentos predeterminados pela coletividade, por meio do Direito, e em benefício desta, para reforço da solidariedade social.

Assim, portanto, o Estado que não presta respeito à regra de Direito não é um Estado legítimo, porque usa sua força e sua elevada potencialidade em momento não autorizado pela sociedade, em benefício de si próprio e dos seus interesses (BILLIER; MARYIOLI, 2007, p. 270).

\section{CONSIDERAÇ̃̃ES FINAIS}

Constituiu objetivo desta pesquisa, reconstruir o percurso teórico trilhado por Duguit para sua construção doutrinária do Estado e do Estado de Direito pelo Direito.
Por isso fez-se necessário investigar as bases fundamentais em que se assenta a sua doutrina, a saber, o organicismo evolucionista, cujo maior expoente foi Herbert Spencer e a sociologia experimentalista de Durkheim, para desvendar até que ponto foram decisivas para Duguit, e em que ponto o autor as utilizou.

E viu-se que o diálogo com esses autores, aliada à influência recebida, foi intensa e decisiva para o desenvolvimento da sua obra.

Essa consistiu, aliás, em uma das maiores preocupações da pesquisa: deixar claro, ante a malversação da sua teoria e das suas bases, em que sentido Spencer e Durkheim influenciaram o pensamento de Duguit.

De outro lado, buscou-se elaborar uma pesquisa que não apenas deixasse evidenciado o percurso decorrido pelo autor, mas, sobretudo, as suas ideias marcantes dentro da Teoria do Estado. A introdução da ideia de que o Estado está a serviço da sociedade para reforço e proteção do seu traço marcante, a solidariedade, recupera a noção do contrato social de Rousseau e a reaviva em tempos de transformações estruturais da sociedade, da economia e do Direito a discussão em torno da função social do Estado e da sua razão de existir.

Aliás, a ideia de função social sempre muito viva na obra de Duguit introduziu importantes e necessárias transformações na concepção atual dos direitos subjetivos, isto é, implicou no reconhecimento de que os direitos individuais exercem determinada função social e cedem determinado perímetro espacial em benefício da sociedade.

A restrição do objeto de pesquisa em torno da elucidação das suas ideias a partir da reconstrução histórica das influências teóricas que recebeu teve, por isso mesmo, somente uma motivação: oferecer um texto claro e "limpo" de juízos críticos ante a consideração de que León Duguit ainda é pouco estudado e mal compreendido. 
As considerações críticas da obra ficam para um próximo artigo que tenha tal propósito. Até lá, no entanto, ficam-se as reflexões, que agora tomam como ponto de partida, ou pelo menos consideram, o pensamento de Duguit.

\section{REFERÊNCIAS}

ARAUJO, Saulo de Freitas. Uma visão panorâmica da psicologia científica de Wilhelm Wundt. Scientiae studia, São Paulo, v.7, n.2, jun. 2009. Disponível em: $\quad<$ http://www.scielo.br/scielo.php?pid=S1678-31662009000200003 \&script=sci_arttext $>$. Acesso em: 28 nov. 2013.

BILLIER, Jean-Cassien. MARYIOLI, Aglaé. História da filosofia do direito. Lisboa: Instituto Piaget, 2007.

BUTTEL, Frederick H. A sociologia e o meio ambiente: um caminho tortuoso rumo à ecologia humana. Revista Perspectivas, São Paulo, v.15, 1992. Disponível em: <http://seer.fclar.unesp.br/perspectivas/article/viewFile/1961/1599>. Acesso em: 28 nov. 2013.

COSTA, Cristina. Sociologia - Introdução à ciência da sociedade. São Paulo: Moderna, 2005.

DRI, Clarissa Franzoi. Antiformalismo jurídico e direito internacional: teoria e prática à luz do pensamento de Georges Scelle. Revista Eletrônica da Faculdade de Direito da PUC-SP, São Paulo, v.3, 2010. Disponível em: <http://revistas.pucsp.br/index.php/red/article/view/2033/3955>. Acesso em: 1 dez. 2013.

DUGUIT, León. L'État, les gouvernements et les agents. Paris: Albert Fontemoing Éditeur, 1903.
DUGUIT, León. Manuel de droit constitutionnel. 4.ed. Paris: Anciennes Maisons Thorin et Fontemoing, 1923.

DUGUIT, León. Traité de Droit Constitutionnel. 3.ed., v.2. Paris: Acienne Librarie Fontemoing \& Cie, 1923.

DUGUIT, León. Les transformations générales du droit prive depuis le code Napoléon. Paris: Alcan, 1912.

DURKHEIM, Émile. Trad. de Eduardo Brandão. Da divisão do trabalho social. São Paulo: Martins Fontes, 1999.

DURKHEIM, Émile. Trad. de Paulo Neves. As regras do método sociológico. São Paulo: Martins Fontes, 2007.

LARAIA, Roque de Barros. Da Ciência Biológica à Social: a trajetória da antropologia no século XX. Revista Habitus, Goiânia, v.3, n.2, jul./dez. 2005. Disponível em: <http://seer.ucg.br/index.php/habitus/ article/viewFile/63/59>. Acesso em: 1 dez. 2013.

REALE, Miguel. Filosofia do direito. 19.ed. São Paulo: Saraiva, 2002.

REALE, Miguel. Teoria do direito e do estado. 5.ed., rev. São Paulo: Saraiva, 2000.

SABADELL, Ana Lucia. Manual de sociologia jurídica: introdução a uma leitura externa do direito. 5.ed. ver. atual. amp. São Paulo: Revista dos Tribunais, 2010.

SOARES, Alisson Magalhães. Sociologia e Sociobiologia: autonomia vs. (sócio)biologização da sociologia. Dissertação (Mestrado em Sociologia) - Departamento de Sociologia e Antropologia, Universidade Federal de Minas Gerais, Belo Horizonte, 2009. 
Recebido em: 26 de março de 2014 Avaliado em: 02 de abril de 2014 Aceito em: 02 de abril de 2014
1. Advogado, Mestrando em Direito Constitucional pela Faculdade de Direito da Universidade de Coimbra. pimentel.ian@hotmail.com 